\title{
(2) OPEN ACCESS \\ Impact of the COVID-19 pandemic on a respiratory physiology department and the patient's perception of rapid service change
}

\author{
Ian Cliff (D) ,' ${ }^{1}$ Naveed Mustfa, ${ }^{2}$ Imran Hussain, ${ }^{2}$ Emma Munro, ${ }^{1}$ Hayley Bishop, ${ }^{2}$ \\ Helen Stone ${ }^{2}$
}

1 Respiratory Physiology,

University Hospitals of North Midlands NHS Trust, Stoke-onTrent, UK

${ }^{2}$ Respiratory Medicine, University Hospitals of North Midlands NHS Trust, Stoke-onTrent, UK

\section{Correspondence to} Ian Cliff, Respiratory Physiology, University Hospitals of North Midlands NHS Trust, Stoke-onTrent, UK; ian.cliff@uhnm.nhs.uk

Received 11 February 2021 Accepted 10 January 2022
Check for updates

(C) Author(s) (or their employer(s)) 2022. Re-use permitted under CC BY-NC. No commercial re-use. See rights and permissions. Published by BMJ.

To cite: Cliff I, Mustfa N, Hussain I, et al. BMJ Leader Published Online First: [please include Day Month Year]. doi:10.1136/ leader-2021-000463

\begin{abstract}
Background Originating as a cluster of unexplained cases of pneumonia in Wuhan, China, a novel coronavirus disease, officially named as COVID-19 by WHO, has now reached a pandemic level. In the wake of this global health crisis, stringent public health measures were implemented to curtail the spread of COVID-19. At a local level, the University Hospitals of North Midlands National Health Service Trust suspended all elective and outpatient activity, primarily to address the current potential implications of the COVID-19 outbreak. Within respiratory physiology, all but urgent and emergency work was suspended.
\end{abstract}

Methods In June 2020, the service commenced its restoration/recovery plan, which was based on national and international guidelines to ensure safe practice for patients and staff alike. The plan was a roadmap developed to upscale the respiratory physiology service to deliver urgent and routine care and to assist the service to undertake the essential task of managing the patient backlog as a consequence of the interruption of service. Patient concerns and anxieties due to the pandemic was a key aspect of the restoration/recovery plan. The service developed numerous initiatives along with a questionnaire to assess patient experience following attendance for investigations or assessment. Results The questionnaire confirmed that the initiatives put in place as part of the restoration/ recovery plan achieve high levels of satisfaction in terms of communication, interaction within the service, professionalism and importantly patient safety.

Conclusion COVID-19 had a significant impact on routine clinical care and out-patient activity. This brought about significant change in service delivery that required a strict regimen to ensure COVID-19 free status and minimise cross-contamination of service users. The systems and processes introduced demonstrated positive responses and confirmed the objective of patient safety, which translated to the service users.

\section{INTRODUCTION}

Respiratory physiology provides vital support to numerous patient pathways to accurately diagnose and clinically manage respiratory and nonrespiratory disorders. COVID-19, the worst pandemic of a generation, has presented healthcare with the most demanding challenges ever, and has resulted in the rapid publication of guidelines to manage patients who are acutely unwell with COVID-19 as well as guidance on managing all aspects of care including how to safely perform respiratory physiology tests. ${ }^{1}$ At the start of the pandemic, respiratory physiology suspended routine clinical activity and redeployed staff to manage the acute element of the outbreak. This paper is an account of the restoration/recovery plan that was implemented to restore physiology services in an acute Trust. It also details patient perception of being invited into a clinical service within the midst of a pandemic and their insight to safety.

\section{Response to COVID-19}

In March 2020, in response to guidance from National Health Service (NHS) England, the University Hospitals of North Midlands NHS Trust suspended all elective and out-patient activity, primarily to address the potential implications of the COVID-19 outbreak for patients. Within respiratory physiology, all but urgent and emergency work stopped. Staff were redeployed to provide vital support in the treatment of critical patients with acute continuous positive airway pressure. ${ }^{2}$ In June 2020, the service started to commence its restoration/recovery plan, which was based on the guidance from Public Health England, the Association for Respiratory Technology and Physiology and the European Respiratory Society to ensure safe practice for patients and staff alike. ${ }^{3-5}$

\section{Restoring services}

The restoration/recovery plan was developed to streamline the restructuring of urgent and routine respiratory physiology services and to address the patient backlog due to COVID-19. The plan included reassessment of infection prevention measures, validation of waiting lists, communication, appointment letters, clinic structures, staffing requirements, room and equipment preparation, room air changes per hour $(\mathrm{ACH})$ along with alternative systems and processes to realise the new way of working. Furthermore, to instil patient confidence, additional safety measures were introduced through preappointment questioning prior to and on the day of appointment, temperature checks, the mandatory wearing of face masks, social distancing, one-way systems and active engagement of patient feedback.

\section{Restoration and recovery}

To ensure a safe and functional environment, service redesign was paramount and consisted of the wearing of full personal protective equipment (PPE) when performing aerosol-generating procedures 
(AGP) and standard PPE for all other non-AGP investigations. Numerous respiratory physiological investigations performed are considered AGP and include cardiopulmonary exercise testing and bronchial provocation. However, non-AGP investigations are associated with cough that has the potential to generate aerosol droplets necessitating strategies to minimise risk. ${ }^{1}$ These result in significant barriers to patient flow. The interval between patients testing (downtime) is dependent on the clinic room air changes per hour $(\mathrm{ACH})$ and whether they were mechanically or naturally ventilated. A typical mechanically ventilated treatment room should be more than $11 \mathrm{ACH}$, which requires a $20 \mathrm{~min}$ period between patients plus $10 \mathrm{~min}$ for cleaning. ${ }^{6}$ The ACH of a naturally ventilated room is dependent on numerous factors (window/door opening, atmospheric conditions, rate of natural air flow) and is often less than $6 \mathrm{ACH}$, resulting in a 90 min downtime period as directed by local policy. ${ }^{7}$ This reduced performance efficiency by $38 \%$ in the department and had a profound impact on service capacity and response to the demand. Previously, the service tested an average of 42 patients/day depending on the nature and type of investigations performed and could accommodate more than 60 patients/day during busy periods. The impact of aerosol generation and the risk of cross-infection reduced this to a maximum of 26 patients/day.

Due to the service response as a consequence of the COVID-19 pandemic, the patient waiting lists increased by over 1500 patients from March to June. The waiting lists were managed based on clinical need with new and existing referrals (partial booking waiting lists) reviewed daily. New referrals to the physiology department were triaged and booked in line with the clinical pathway (cancer, oxygen management, admission avoidance). In addition, dialogue was sought with original referrers to agree appropriate management, which may include, 'watch and wait', triaged as urgent (eg, surgery for cancer, significant clinical decline, interstitial lung disease patients' assessment for consideration of treatment), deferring tests, suggestion of alternative investigation/s or complete removal (no longer required). Investigations provided during March to May included dynamic spirometry and oxygen therapy service for both long-term and ambulatory provisions.

Changes to clinic structure allowed for staggered appointment times as opposed to block attendance to facilitate controlled patient flow. The patient was contacted before their appointment to stipulate attendance close to their appointment time, and to be unaccompanied where possible (online supplemental information). Implementation of a 'runner system' was developed and supported departmental flow. The 'runners' directed departmental operations from greeting patients on arrival to escorting out of the clinical area (via a one-way system), ensure adherence to social distancing, prepare rooms for testing and assisting staff or patients where needed. Staff performing investigations were limited to the clinical room while testing, and the runners were key in ensuring minimal aerosol exposure to communal areas. In addition, a business case was prepared to secure funding to implement ventilation to all naturally ventilated areas within the department.

The department introduced extended working days and intermittent 6-day working as a way to reduce the impact on the backlog waiting list, and to meet the increased demand as other services embarked on their own restoration/recovery plans. The initiatives have realised increased capacity while ensuring a safe clinical environment for the patients and staff alike. Figure 1 shows the capacity pre-COVID, cessation of routine outpatient work and performance as part of the restoration/recovery.

The service redesign has been delivered through service/ quality improvement with no additional scientific staffing nor administration support, however, additional working hours have been supported by the team, which equates to 2 days per month. Supplementary resource has been seen through PPE and the

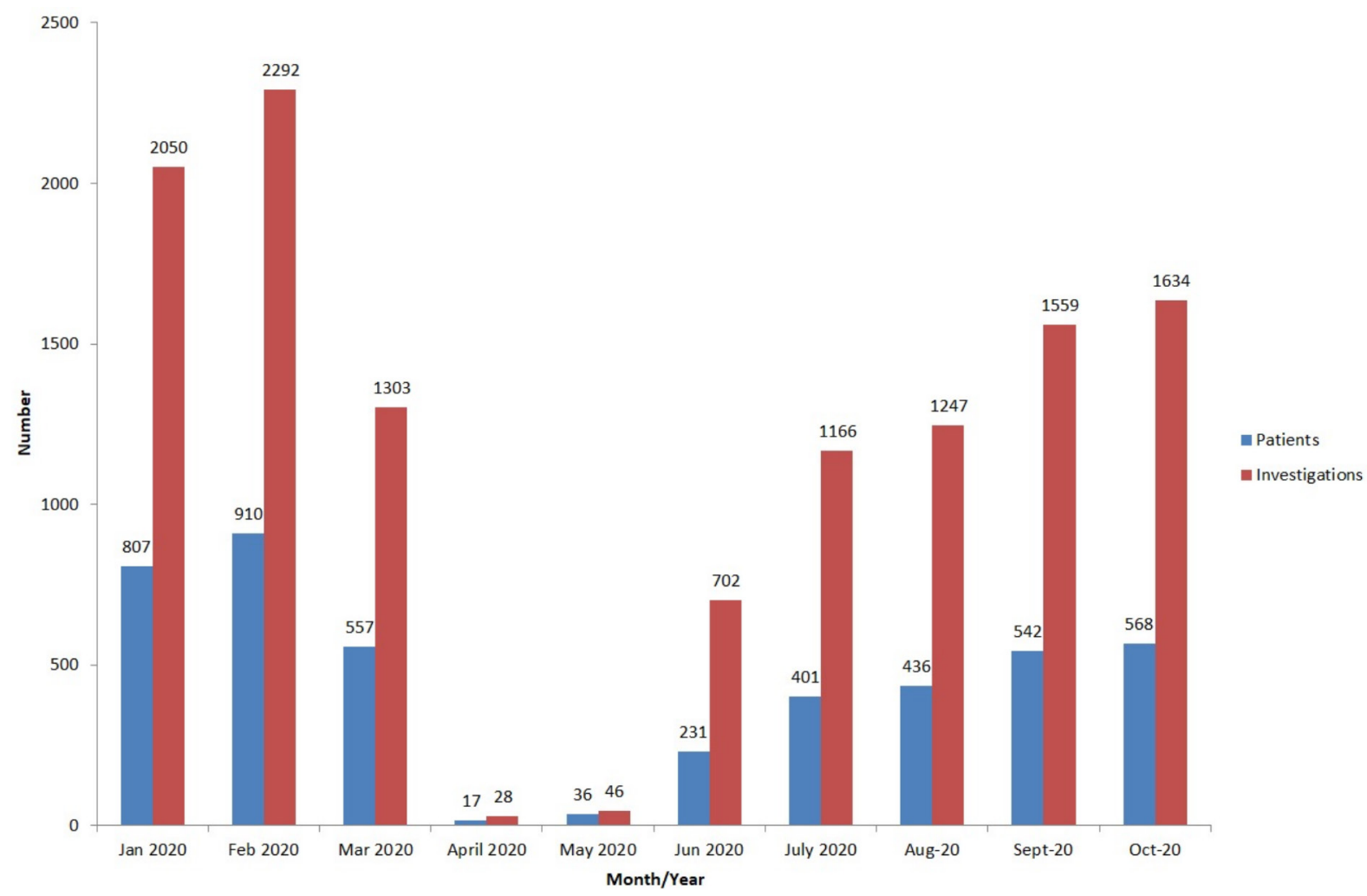

Figure 1 Respiratory physiology performance by patients seen and investigations performed. 
1. Did you receive sufficient pre-test instructions and information prior to your appointment? Yes or No

2. When you arrived at the department were you greeted promptly by a member of the respiratory team?

Yes or No

3. How would you rate the professionalism, teamwork and communication of the staff today?

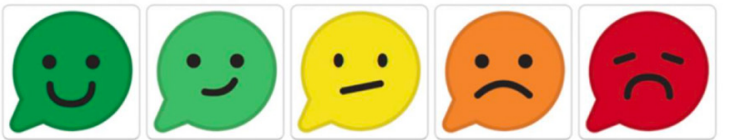

4. Were all possible measures taken to ensure your safety today? Yes or No

5. How would you rate the cleanliness of the department?
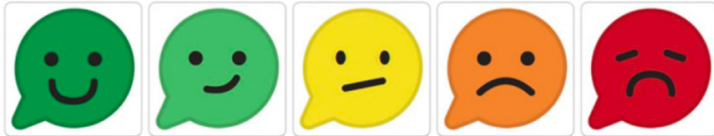

6. Briefly how could we improve the service we provide?

Free text

Figure 2 Patient feedback questions.

redistribution of equipment (ie, computer on wheels, etc) from areas throughout the organisation.

\section{Patient feedback}

Patient concerns as a result of the pandemic were a key aspect. In order to gain both an understanding of the measures put in place as part of the restoration/recovery plan, and to understand patients' anxieties, a patient feedback questionnaire was developed. The patient feedback was achieved through an electronic questionnaire (figure 2) that was completed following the clinic appointment, ${ }^{8}$ which consisted of six questions with the ability to add comments through free text.

The questions were designed explicitly to assess the patients' perception of the measures implemented as part of the restoration/recovery plan, and how they impacted their experience when attending for their appointment within the department. The output report was generated to provide constructive feedback to enhance the service further and to meet the needs of the patients it serves. A section of the documented feedback from 8th June 2020 to 14 th October 2020 can be seen below in figure 3 and included over 900 patient responses.

\section{Analysis of the responses}

The feedback questionnaire provided an essential understanding of how the service is perceived by patients, along with areas of concern and improvement. Over $95 \%$ of the respondents indicated that the pretest instructions were sufficient for their needs. Further analysis highlighted that patients attending on Tuesdays had significant problems, which related specifically to urgent investigations that were requested over the previous weekend. The majority of these appointments were arranged by telephone due to insufficient time to post an appointment letter and patient information sheet.

To ensure social distancing could be maintained it was essential to manage the flow of patients through the department and avoid crowding of individuals within wait areas. Ninety-eight
○ Did you receive sufficient pre-test instructions and information prior to your appointment? (996)

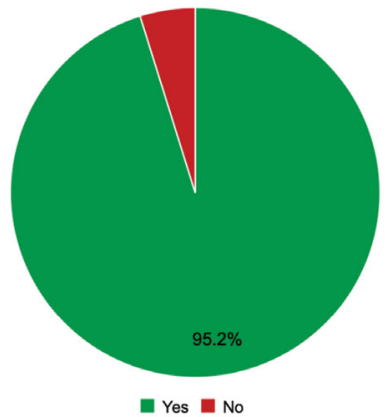

O How would you rate the professionalism, teamwork and communication of the staff today? (927)

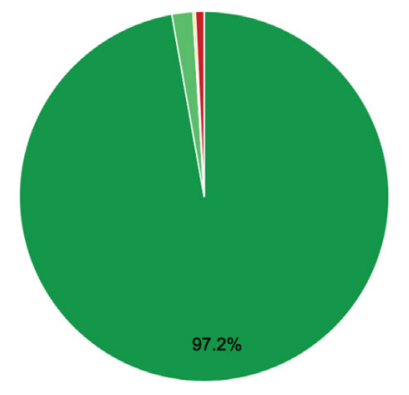

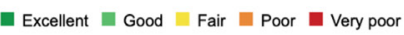

OWere all possible measures taken to ensure your safety today? (918)

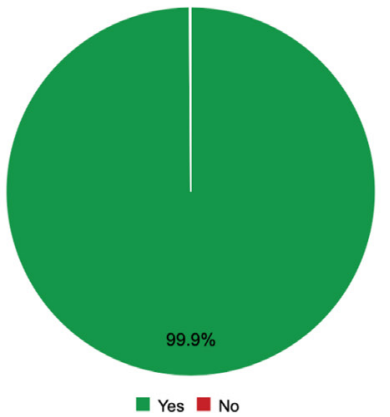

Figure 3 Patient responses.

per cent of patients felt they were greeted promptly by a member of the respiratory team.

Of the 927 patients responding, 99\% felt that the professionalism, teamwork and communication was 'good to excellent'. This specifically looks at the teams adherence to the Trusts values and promise, which underpins the vision of the organisation to be a world- class centre of clinical and academic achievement, where staff work together to ensure patients receive the highest standards of care and the best people want to come to learn, work and research. ${ }^{9}$

Patient safety is paramount, and it is vital that any patient attending the Trust feels confident and safe without concern or worry. Sixty-nine per cent of the patients referred to the service from April to October 2020 were from within respiratory medicine with many classed within the clinically vulnerable group of patients. Over 99\% of the responding patients felt all possible measures regarding their safety had been considered. This would suggest that the measures put in place as part of the restoration/ 
recovery plan were successful and that the organisation was committed to both welcoming patients back and that their safety was of the utmost importance.

Respiratory physiology is based within a purpose-built department that adheres to accepted standards of clinical physiological provision. ${ }^{10}$ The service is regularly audited for cleanliness in terms of infection prevention and control. Over 99\% of the responding patients rated the departments' cleanliness as 'good to excellent' and once again reinforced the commitment to patient safety.

Finally, the patient narratives gave an insight into how the department was perceived through the lens of the patients. The comments were overwhelmingly positive, however there were a number of areas highlighted that warrant further investigation and action, which often related to communication for urgent appointments.

\section{Bias and limitation}

The authors accept there are limitations and bias in the methodology implemented within this paper. The patient population only included patients willing to attend for ongoing clinical care and thus excluded the opinions of those who declined an appointment or who failed to attend. During this period there were $237(11 \%)$ patients who did not attend for their appointment despite confirming beforehand that they would attend. Unfortunately, data for all individuals who declined an appointment is not available, however, from September to October 2020 reasons for declining an appointment included; patient ill, chest infection, unable to attend or work commitments as reasons for not attending, which would suggest the number declining due to concerns of COVID-19 are small. Those who did not attend may have been concerned about the risk of COVID-19, but it is not possible to capture that data.

\section{Recommendations}

The challenge of the restoration/recovery plan was to maintain services, increase capacity and manage service demand/capacity while providing a safe environment for patients, staff and visitors. Maintaining services will require a continuous review of current practice throughout the pandemic based on emerging evidence, developing guidance and expert opinion. Table 1 highlights the main recommendations from our experience.

The respiratory physiology team, with medical and management support demonstrated clear leadership in the ever-changing environment that COVID-19 presented. As the pandemic evolved, the unprecedented decision to close the service was rapidly made to protect both patients and staff. As knowledge and understanding advanced, a robust restoration/recovery plan was developed to deliver against infection prevention and clinical need. Reassessing, redesigning and reassigning roles allowed improved patient flow through the department and service change to occur with minimal additional cost. Following the reinstation of provision, patients' perceptions were actively sought to assess public confidence and to understand their concerns regarding returning to a healthcare setting following a period of 'lockdown'. The leadership exhibited within the paper has demonstrated its importance in both patient safety and developing services to minimise risk while ensuring an effective clinical service.

\section{CONCLUSION}

COVID-19 had a significant impact on routine clinical care and outpatient activity. This was primarily to ensure an appropriate resourced response to the pandemic. A respiratory physiology department within an acute tertiary Trust reduced its service to all but urgent and cancer referrals for 3 months. The restoration/recovery plan evolved with advice and guidance from both national and international organisations and societies to ensure both the safety of patients and staff alike. Furthermore, support from infection prevention and control departments' ensured adherence to the local policy. This brought about significant change in service delivery that required a strict regime to ensure COVID-19 free status and minimise cross-contamination of service users.

We have demonstrated a model that complies with infection prevention measures, maximises capacity within restraints and

Table 1

Infection prevention and control (IPC)

Training in IPC measures should be provided to all staff.

The correct use of PPE (including a face fit test if wearing a filtering face piece 3) and the correct technique for donning and doffing safely.

Decontamination of equipment and hand hygiene facilities.

Aerosol generating procedures (AGP)

Social distancing

Occupational health

Respiratory department
Prioritising patients to manage demand

\section{Consideration of whether investigations/assessments are AGP or non-AGP and the implications of such.}

Establish separate patient and staff flow to minimise the spread of infection. One-way systems, clear signage and/or restricted access to certain areas. Remote consultations rather than face to face should be offered to patients/individuals.

Prompt recognition of COVID-19 symptoms among healthcare staff with a clear testing process. Outbreaks within specific areas to be isolated to prevent further spread.

Risk assessment for all staff (clinically extremely vulnerable—home working or redeployed).

All appointment letters include a COVID-19 information sheet specific to the trust.

A preappointment telephone call as a COVID-19 screening tool thus enabled the patient to confirm their attendance and any concerns addressed.

Contraindications for lung function, COVID-19 symptoms and recent travel also checked to minimise unused slots/DNAs. $\mathrm{ACH}$ (mechanical vs natural) and relevance of downtime between patients and identify real estate capacity and ensure compliance with IPC protocols.

Define urgent or routine by the referrer.

Factors to be considered:

- Date of follow-up appointment booked.

- Correlate with referrer's waiting list entry (follow-up delayed, adjusted timeframes to match).

- Patients clinically vulnerable/isolating.

- Communication with the referrer

- May be preferable to avoid same day spirometry to help comply with social distancing in patient waiting areas

$\mathrm{ACH}$, air changes per hour; PPE, personal protective equipment. 
limitations, while demonstrating positive patient feedback. Moreover, the NHS Track and Trace service has highlighted several patients who were COVID-19 positive while attending the department for investigations, however, no staff member has tested positive for COVID-19 to date through lateral flow or PCR testing, proving the safety measures we have implemented are sufficient to keep staff as well as patients safe.

Acknowledgements The authors would like to acknowledge the respiratory physiology staffs, the directorate management team and the respiratory medical team for their support during this project.

Contributors $\mathrm{IC}$ is head of respiratory and sleep physiology services and has overseen this paper in terms of design, planning and retrieving the information within. Furthermore, he has been the main author for analysing the data and the writing of the paper. EM has contributed to clinic structure, room and staff utilisation and managing of waiting lists within the restoration recovery plan. In addition, she monitored and allocated appointments based on clinical need, with support from the medical staff (HS, NM and IH). Furthermore, she has contributed to the writing and editing of the paper. HS was instrumental in reviewing patient waiting lists and liaising with non-respiratory teams for the appropriate allocation of patient appointments. She has contributed to the writing and editing of the paper. NM development the restoration of the respiratory physiology service in terms of infection prevention and control. He developed many of the standard operating procedures as a response to the pandemic and contributed to the development of the patient feedback questionnaire. NM liaised with the audit department and obtained the relevant assurance that the contents of the paper was a service review and as such, was excerpt from ethical approval. He has also contributed to the writing and editing of the paper. HB oversaw the restoration/recovery plan from a Trust management perspective, which included support for PPE, assessment of facilities, liaising with the PFI company and allocation of resources. She has contributed to the writing and editing of the paper. IH oversaw the suspension of routine services at the start of the pandemic. He is the lead consultant for lung cancer and was vital in supporting the respiratory physiology to meet the need of not only the cancer service, but all urgent referrals within the trust. He was a main contributor for the development of the questionnaire. He has also contributed to the writing and editing of the paper.

Funding The authors have not declared a specific grant for this research from any funding agency in the public, commercial or not-for-profit sectors.

\section{Competing interests None declared.}

Patient consent for publication Not applicable.

Ethics approval This study involves human participants but authorisation was obtained from Quality, Safety and Compliance Department at the University Hospitals of North Midlands NHS Trust exempted this study.

Provenance and peer review Not commissioned; externally peer reviewed.
Supplemental material This content has been supplied by the author(s). It has not been vetted by BMJ Publishing Group Limited (BMJ) and may not have been peer-reviewed. Any opinions or recommendations discussed are solely those of the author(s) and are not endorsed by BMJ. BMJ disclaims all liability and responsibility arising from any reliance placed on the content. Where the content includes any translated material, BMJ does not warrant the accuracy and reliability of the translations (including but not limited to local regulations, clinical guidelines, terminology, drug names and drug dosages), and is not responsible for any error and/or omissions arising from translation and adaptation or otherwise.

Open access This is an open access article distributed in accordance with the Creative Commons Attribution Non Commercial (CC BY-NC 4.0) license, which permits others to distribute, remix, adapt, build upon this work non-commercially, and license their derivative works on different terms, provided the original work is properly cited, appropriate credit is given, any changes made indicated, and the use is non-commercial. See: http://creativecommons.org/licenses/by-nc/4.0/.

\section{ORCID iD}

Ian Cliff http://orcid.org/0000-0003-4466-088X

\section{REFERENCES}

1 Hull JH, Lloyd JK, Cooper BG. Lung function testing in the COVID-19 endemic. Lancet Respir Med 2020;8:666-7.

2 Barker J, Oyefeso 0, Koeckerling D, et al. COVID-19: community CPAP and NIV should be stopped unless medically necessary to support life. Thorax 2020;75:367-67.

3 Public Heath England. New personal protective equipment (PPE) guidance for NHS teams, 2020. Available: https://www.gov.uk/government/news/new-personalprotective-equipment-ppe-guidance-for-nhs-teams [Accessed 7 Oct 2002]

4 Association for Respiratory Technology \& Physiology. ARTP COVID 2020. Available: https://www.artp.org.uk/News/artp-covid19-update-18th-march-2020 [Accessed 7 Oct 2020]

5 European Respiratory Society. Lung function testing during COVID-19 pandemic and beyond, 2020. Available: https://ers.app.box.com/s/zs1uu88wy51monr0ewd990it oz4tsn2h [Accessed 7 Oct 2020].

6 Public Heath England. COVID-19: guidance for the remobilisation of services within health and care settings. infection prevention and control recommendations, 2020. Available: https://assets.publishing.service.gov.uk/government/uploads/system/ uploads/attachment_data/file/910885/COVID-19_Infection_prevention_and_control_ guidance_FINAL_PDF_20082020.pdf [Accessed 18 Nov 2020].

7 Gilkeson CA, Camargo-Valero MA, Pickin LE, et al. Measurement of ventilation and airborne infection risk in large naturally ventilated hospital wards. Build Environ 2013;65:35-48.

8 Viewpoint. ViewPoint Pulse 2020 [Questionnaire]. Available: https://www. viewpointfeedback.com/vp-pulse/ [Accessed 7 Oct 2020].

9 University Hospitals of North Midlands. Our organisation, 2020. Available: https:// www.uhnm.nhs.uk/about-us/our-organisation/ [Accessed 14 Oct 2020].

10 United Kingdon Accreditation Service. Improving quality in physiological services (IQIPS), 2016. Available: https://www.ukas.com/services/accreditation-services/ physiological-services-accreditation-iqips/ [Accessed 20 Oct 2020]. 